\title{
COPIAR, COLAR, REPETIR: A POESIA EM DESLOCAMENTO DE MARÍLIA GARCIA E SEUS EFEITOS SOBRE A LEITURA NA ERA DA CULTURA DIGITAL
}

\author{
MARIANA COBUCI SCHMIDT BASTOS (USP) ${ }^{1}$
}

\begin{abstract}
RESUMO: Este texto reflete sobre os procedimentos utilizados pela poeta Marília Garcia em seus livros um teste de resistores e Câmera lenta (publicados em 2014 e 2017, respectivamente) a fim de promover o que podemos chamar de uma poética do deslocamento. A partir de uma série de trechos de poemas de Marília, mostra-se como a poeta se vale de procedimentos como os de copiar, colar (citar) e repetir. Trata-se de procedimentos comuns à cultura digital, mas que na poesia de Marília operam de outro modo, mais devagar e atento. Dessa exposição e discussão, depreende-se que a proposição de outro ritmo, somada à reflexão sobre a linguagem que existe nessa poesia, sugere outros modos de lidar com a rapidez da época em que vivemos, além de incentivar um novo modo de ler dentro da cultura digital, um modo mais pessoal, curioso e ativo.
\end{abstract}

PALAVRAS-CHAVE: Marília Garcia. Poesia contemporânea. Deslocamento. Cultura digital. Leitura.

\begin{abstract}
This text analyses procedures used by poet Marilia Garcia in her books "um teste de resistores" and "Câmera lenta" (published in 2014 and 2017, respectively) which promote what we may call a poetics of displacement. Considering a series of excerpts from Marilia's poems, we will show how the poet uses procedures such as copying, pasting (quoting) and repeating. These are procedures common to digital culture, but which in Marilia's poetry operate in a different way, more slowly and attentively. From this exposition and discussion, it will appear that the proposition of another rhythm, added to how this poetry thinks about language, suggests other ways of dealing with the high speed of our time, while encouraging a new way of reading inside digital culture - a more personal, curious and active way.
\end{abstract}

KEYWORDS: Marilia Garcia. Contemporary poetry. Displacement. Digital culture. Reading.

\section{INTRODUÇÃO}

Desde 2007, quando publicou seu primeiro livro, 20 poemas para seu walkman, a poeta carioca Marília Garcia mostra-se interessada por uma poética do deslocamento - entendido tanto como a movimentação do sujeito que explora espaços, virtuais ou não, como o deslocamento de sentidos, usos linguísticos e tempos para outros lugares e momentos. Um dos aspectos de sua poesia que mais chama a atenção (e que é radicalizado em suas últimas publicações), acredito, é a proposição de outro ritmo nesse deslocar, um ritmo, como o título de seu último livro indica, mais demorado e atento como que em Câmera lenta (Companhia das Letras, 2017).

Sua poesia não se volta simplesmente aos assuntos do cotidiano, mas ao que Georges Perec (2015) chamou de infra-ordinário, questionando-se sobre como fazer ver o que se esconde no evento mais aparentemente banal, como descrevê-lo, como aproximar-se do que sempre existe por detrás dos acontecimentos e das coisas. O que

\footnotetext{
${ }^{1}$ Mestra em Letras pela Universidade de São Paulo e doutoranda (bolsista CNPq) no Programa de PósGraduação em Literatura Brasileira pela mesma Universidade, sob a supervisão do Prof. Dr. Ivan Francisco Marques. E-mail: mariana.cobuci.bastos@usp.br
} 


\section{$=$ TRAMA $=$}

o sujeito poético procura apreender, como ressaltou Andréa Catrópa (2018), é, mais do que o próprio acontecimento cotidiano, a forma como ele é apresentado, e quais são seus mecanismos subjacentes - "talvez a gente pudesse fazer silêncio / e de repente neste silêncio / acontecer de ouvir algo por detrás / dos ruídos das máquinas voadoras que / cruzam o céu." (GARCIA, 2017, p. 12)

Para "deixar a escuta aberta" e explorar o espaço entre as coisas ("seria possível ver o que está / no meio?" (2017, p. 44), movimentando-se desse modo, a poeta se vale de uma série de procedimentos poéticos. Podemos afirmar que esses procedimentos são bastante contemporâneos, uma vez que se pautam pela forma como muitas das nossas relações, hoje, são mediadas por tecnologias e comunicações digitais, pelo fenômeno transmídia, pelo fluxo de informações por meio da internet, pela interatividade constante. O próprio interesse da poeta por uma "poética do deslocamento" já diz algo sobre sua imersão e reflexão acerca da cultura digital, que é, entre outras coisas, uma cultura da transferência, transferência de informações, imagens, opiniões, textos, mensagens, onde nos movimentamos o tempo todo por diferentes páginas e aplicativos criados por diferentes pessoas ao redor do mundo.

Em Câmera lenta - mas não só nele, já que essas questões em Marília são trabalhadas enquanto pesquisa, com forte caráter reflexivo, desdobrando-se de livro a livro -, a poeta favorece o deslocamento (da poesia, do poema, do leitor, do autor) por meio de procedimentos como o recorte, a colagem e a repetição. Procedimentos comuns à cultura digital mas que, em seus poemas, parecem se guiar não pela velocidade frenética ou pelo desejo de estabelecer uma visão homogênea dos acontecimentos, mas pelo deslocamento demorado, para, lado a lado com o outro (outras vozes da literatura, o leitor, o sujeito que se faz e refaz durante a escrita) a quem, como formulou Silviano Santiago (2013), o poema sempre se destina, reaprender a ver, não só produzindo alguma coisa que ainda não foi vista, mas principalmente promovendo um modo específico de lidar com o fluxo de informações - um modo de se constituir enquanto sujeito nessa dinâmica acumulada de textos.

Trata-se, portanto, de produzir, formalmente, um deslocamento, uma movimentação, e não apenas de falar sobre isso:

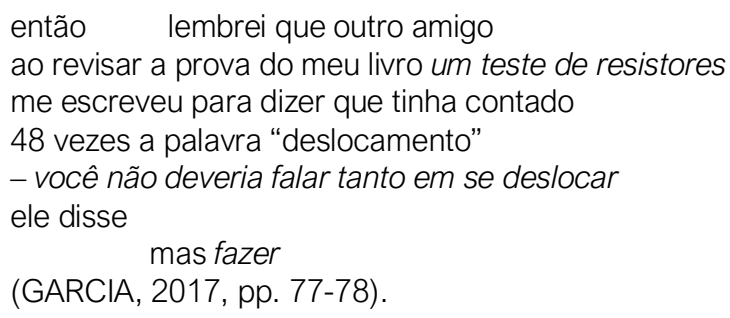

O diálogo que a poesia de Marília Garcia estabelece com ou propõe à cultura digital é outro, mais lento, que se apropria da possibilidade contemporânea de percorrer e acessar quase tudo do que já foi feito e dito para, sendo de outro modo, chegar a outros lugares, estar no pensamento de outras coisas junto ao outro do poema; e, como discutirei mais adiante, parece-me que essa postura da poeta cria, ainda, um novo incentivo à leitura, uma vez que ela escreve também o que pode ser uma experiência de leitura, propondo uma maneira ativa, pessoal e criadora de interagir com as tantas obras lidas, vistas e ouvidas que nos atravessam atualmente. 


\section{$=$ TRAMA $=$}

\section{POESIA E DESLOCAMENTO}

Mas como fazer para que a linguagem se desloque? Marília se questiona durante o livro, reconhecendo que, mesmo (ou talvez por isso?) "neste momento que vivemos / de espaços abertos e infinitos" (2017, p. 78), a possibilidade da paralisia ronda:

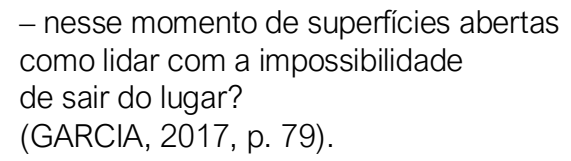

Assumimos que a poesia é, por definição, o deslocamento da linguagem comum, da fala cotidiana, é ela quem tensiona a linguagem. Há, como diz Barthes (2004), forças de liberdade (que são também de destruição) nos textos literários, que operam pelo trabalho de deslocamento exercido sobre a língua. A literatura, diz ele, "faz girar os saberes, não fixa, não fetichiza nenhum deles; ela Ihes dá um lugar indireto, e esse indireto é precioso" (p. 43). Por encenar a linguagem ao invés de utilizá-la de forma utilitária (visando somente a comunicação), a literatura "engrena o saber no rolamento da reflexividade infinita" (p. 46). E nunca se rende ao impossível, é utópica, uma vez que, visando sempre alcançar o real, mas igualmente sabendo da sua impossibilidade, cria formas outras de pensar e de se estar no mundo.

No entanto, escrever um poema não significa operar necessariamente essa destruição produtiva própria da linguagem poética, que faz a língua se mover - "Não basta observar cavalos durante o dia para infalivelmente sonhar com eles à noite, não basta propormo-nos muito obstinadamente contemplá-los em sonho para aí os ver aparecer" (MICHAUX, 2011, p. 1). Para promover algo na língua, fazê-la andar, é necessário experimentar, forçá-la ao seu limite, pois, ainda de acordo com Michaux, a verdadeira poesia se faz contra a poesia. Sem esse exercício exigente (mas não menos prazeroso), corre-se o risco da paralisia.

Marília Garcia sem dúvida é uma poeta que experimenta, que brinca com as palavras, refletindo criticamente sobre suas potencialidades na forma mesma do poema. Nesse sentido, lembro do que escreveu a crítica portuguesa Silvina Rodrigues Lopes, que é, inclusive, mencionada em um poema de Câmera lenta - "só existe pensamento na experimentação" (GARCIA, 2017, p. 84). É testando, jogando com o que já foi produzido, intervindo nele, que se pode seguir pensando. Continuar a pensar tem a ver com o próprio caráter aberto ao múltiplo da poesia, que não se fixa num sentido único, num entendimento absoluto. Busca-se, sobretudo nos poemas de um teste de resistores e Câmera lenta, pôr em jogo a possibilidade da poesia (e aí incluem-se também o leitor e aquele que escreve) de não se tornar imóvel, de seguir fazendo perguntas - "talvez o discurso possa seguir / circulando talvez importe fazer / perguntas / e não definir quem fez / o quê" (2014, p. 19).

$\mathrm{Na}$ poesia de Marília Garcia, mais do que crer que é possível criar algo inteiramente novo, no sentido de inédito, o que faz o pensamento seguir pensando é a possibilidade de caminhar junto de outras vozes, vindas de diferentes suportes.

$(\ldots)$ serve para ler as coisas de outra maneira serve para pensar por exemplo que estamos repetindo muito esse gesto ultimamente ao atravessar os vários suportes 


\section{$=$ TRAMA $=$}

e meios digitais digitando recortando
colando vivendo a
hiperinformação
(GARCIA, 2014, p. 22).

Em seus livros, sobretudo em um teste de resistores e Câmera lenta, Marília experimenta as ferramentas de copiar e colar textos vindos de outros lugares: diálogos de filmes, frases ouvidas por amigos e colegas, perguntas que um espectador fez em alguma de suas apresentações ao público (a poeta cada vez mais vem apostando nessas leituras em voz alta, onde ajusta o poema à sua situação de enunciação, acrescentando, ainda, a exibição de imagens durante a sua leitura), citações de outros autores, versos de outros poetas, reflexões de teóricos e críticos da literatura e de outras artes, notícias de jornal e televisão, imagens de outros livros. Não só copia e cola, mas age sobre essas referências, ou melhor, age com elas, retirando-lhes partes, acrescentando outras, misturando pedaços, fazendo conviver vozes de escritores e pensadores consagrados com falas que escutou de pessoas na rua ou em eventos de literatura. A origem diversificada desses desentranhamentos, a qual à primeira vista nos poderia fazer crer serem recortes de lugares distantes entre si, passam assim a remeter a um lugar comum, posto que todos estão igualmente propícios a aparecerem no aqui e agora do poema. Sendo assim, essas ferramentas favorecem a reflexão sobre as possibilidades da língua, acerca de como, nela, é possível reunir tempos e espaços, e, pela forma como nos movermos nela, nos movermos entre esses tempos e espaços. As diferentes vozes que são trazidas ao corpo de seus poemas não deixam de compor um pensamento sobre a constituição de si mesmo a partir do outro.

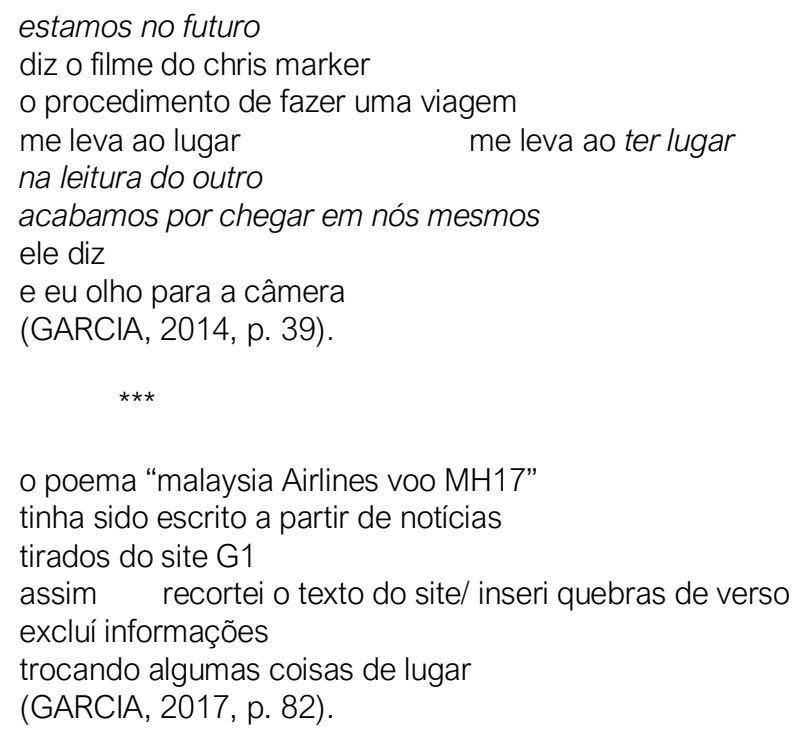

Tais procedimentos, é certo, expõem também as relações entre a poesia moderna e a contemporânea. Segundo Joana Matos Frias e Sofia de Sousa e Silva, a colagem é um

Processo declaradamente moderno e sobretudo vanguardista na sua origem plástica, a colagem marcou de forma decisiva o andamento artístico das primeiras décadas do século XX, tendo tido expressões marcantes mas diferenciadas nas estéticas cubista, expressionista, dada e surrealista, entre outras. Promovendo uma rehierarquização dos 
materiais mediante a sua associação insólita, bem como um enaltecimento das diversas estratégias de apropriação, a colagem não só proporcionou uma reproblematização crítica das relações da arte com o mundo, como o fez ainda relativamente aos conceitos de autoria e autoridade, transgredindo em definitivo as fronteiras entre materiais, campos artísticos, géneros, discursos e práticas criativas. Neste sentido, a colagem converteu-se naturalmente num procedimento elementar e agenciador para a própria escrita poética, no seio da qual teve um impacto flagrante no plano da criação, mas também no da reflexão crítica. À entrada do século XXI, a colagem apresenta-se claramente como uma das manifestações mais emblemáticas e sistemáticas da complexa rede de vínculos intermediais que tem pautado a produção poética, conforme se tem tornado patente em várias exposições, publicações e equacionamentos teórico-críticos por parte de vários artistas e pensadores (2016, p. 5).

Marília explora esse hibridismo herdeiro da poesia moderna, procura e faz emergir o poema que existe fora do livro, num diálogo entre diferentes mídias e textos. Investiga o que Florencia Garramuño (2014), a partir das discussões propostas por Rosalind Krauss (1979), chamou de "literatura fora de si" ou "arte inespecífica". A pesquisadora argentina articula tais conceitos para pensar a literatura contemporânea, que, de acordo com ela, "enfatiza o transbordamento de alguns dos limites mais conspícuos que haviam definido o literário com relativa comodidade, pelo menos até os anos 1960" (p. 33). Os textos contemporâneos, e os de Marília estão incluídos, evidenciam uma forte porosidade de fronteiras. $\mathrm{E}$

$\mathrm{Na}$ aposta no entrecruzamento de meios e na interdisciplinaridade, é possível observar uma saída da especificidade do meio, do próprio, da propriedade, do enquanto tal de cada uma das disciplinas, uma expansão das linguagens artísticas que desborda os muros e barreiras de contenção (GARRAMUÑO, 2014, p. 15).

Em outras palavras, é como se essa literatura fora de si já estivesse quase abnegando de qualquer especificidade de seus suportes, sejam eles as palavras, as imagens, o livro ou o vídeo, e buscasse alcançar o poético para além desses materiais, nos próprios modos de movimentação em um campo único, sem muros e fronteiras formais. É claro que é necessário destacar esse "quase", pois a promoção desse poético não pode acontecer senão através dos próprios suportes, sua desestruturação, deslocamento e por vezes negação explícita. Segundo Garramuño, ainda, para além de questionar o meio das obras, a prática da "literatura fora de si" põe em questão a determinação do sujeito,

(...) do lugar, da nação e até da língua, e a arte inespecífica explora modos de fazer valer com um sentido comum - comum porque é impróprio (...) uma situação, um afeto ou um momento que, ainda quando possa ser muito pessoal, nunca acaba por definir-se através da individualização de uma marca de pertencimento (2014, p. 28).

Esses diálogos intertextuais e intermediais, portanto, promovem a invenção de um comum, de acordo com a pesquisadora argentina. Nos poemas de Marília Garcia, os textos projetam esse comum através de uma espécie de intromissão de vozes. E, nesse aspecto, podemos afirmar que sua poesia herda algo de Ana Cristina Cesar, poeta também carioca que publicou entre meados dos anos setenta e o começo dos anos oitenta, voz destoante da chamada "poesia marginal". 
A presença de diálogos no texto de Ana Cristina foi esmiuçada no importante ensaio de Flora Süssekind, Até segunda ordem não me risque nada, escrito em 1989, mas publicado apenas em 1995. Nele, Süssekind aponta a importância do trabalho de Ana Cristina como tradutora na construção de sua diç̧ão poética - atividade que Marília também exerce, dentro e fora de seus poemas. Trata-se de uma poesia repleta de interferências, uma "poesia-em-vozes", diz a ensaísta.

Os autores que Ana Cristina traduziu foram detidamente selecionados, o que sugere que a poeta buscava possíveis interlocutores, vozes que pudessem ajudá-la a aprimorar seu método poético. Muitos dos textos de outros autores que compõem o de Ana Cristina são traduções que a própria poeta fez - sua escrita sendo entendida como "arte da conversação". Para Michel Riaudel (2015, p. 168), "o recurso à citação/tradição praticado por Ana Cristina dissolve o sujeito em meio a uma profusão de enunciadores". "O 'pessoal', na fala (...) do sujeito lírico em Ana Cristina Cesar, parece apontar, em meio à própria exibição, para descentramento inevitável” (SÜSSEKIND, p. 12).

Esse descentramento tão característico da poesia de Ana Cristina ressoa na de Marília Garcia - que já afirmou reconhecer a influência de Ana C. na poética contemporânea, haja vista que ela abriu portas para várias dessas experimentações intertextuais e intermediais -, muitas vezes formalmente marcado pelo uso das aspas, dos travessões, do itálico, e pela profusão e confusão de pronomes pessoais:

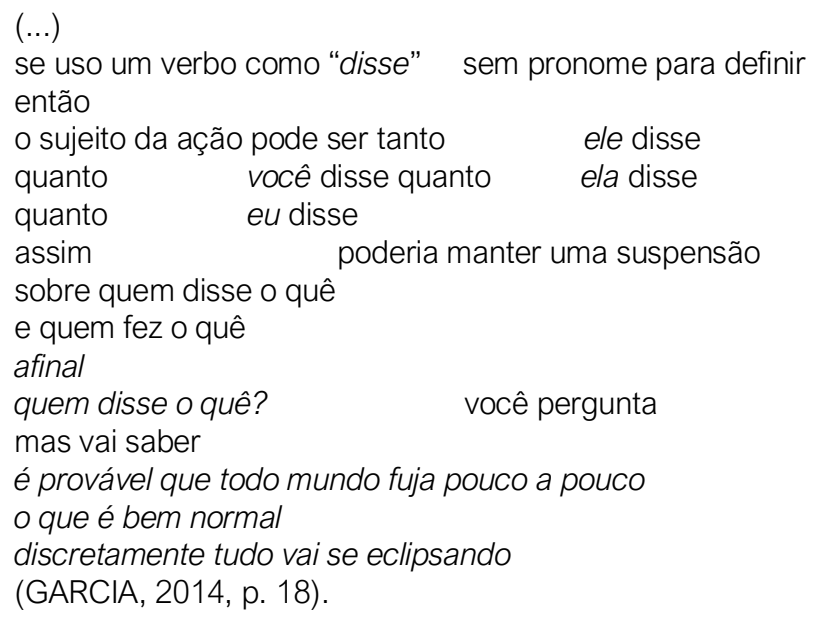

Mas diferentemente dos poemas de Ana Cristina, os de Marília são longos, e se aproximam muito, por se valerem de procedimentos como os da repetição, da oralidade, da fala. Como dito mais acima, a poeta tem frequentemente lido seus poemas em voz alta quando chamada para participar de eventos literários e premiações. Essas performances, segundo a própria poeta, tiveram início quando, ao ser chamada para ler alguns de seus textos de seu primeiro livro, 20 poemas para seu walkman, percebeu que eles foram feitos para serem lidos em voz baixa, em razão de sua sintaxe muito entrecortada. A partir dessa percepção a poeta decidiu ter como questão a feitura de um poema para ser lido em voz alta. Seus poemas a partir de um teste de resistores tornamse, então, mais narrativos, dotados de uma sintaxe mais fluida, sem tantos sobressaltos - outro ponto de distinção que se estabelece entre a sua poesia e a de Ana Cristina Cesar, que, embora desejasse o verso longo e tranquilo, não conseguia evitar os entrecortes e o ritmo galopante.

Nessas leituras públicas, a poeta, também como já mencionado, atualiza "ao vivo" o poema, alterando o que saiu impresso em livro às demandas do local em que está 


\section{$=$ TRAMA $=$}

falando. Essas alterações, acredito, também promovem um deslocamento, fazendo o poema extrapolar os seus limites de dentro do livro para ocupar outros espaços, para se fazer mais presente, atual.

Outra sensação de deslocamento que os poemas provocam, agora retomando as suas versões impressas, dá-se pelos frequentes "buracos" que existem em meio aos versos. Há, em algum lugar do verso, uma distância entre palavras, por vezes, também, um recuo maior do verso em relação ao seu anterior. Esses espaços em branco marcam, pela ausência que provocam, uma movimentação. Como se os versos, ao serem lidos ou escritos, caminhassem. Esses espaços em branco, certos silêncios, possibilitam também a participação do leitor, que pode vir a preenchê-los de algum modo.

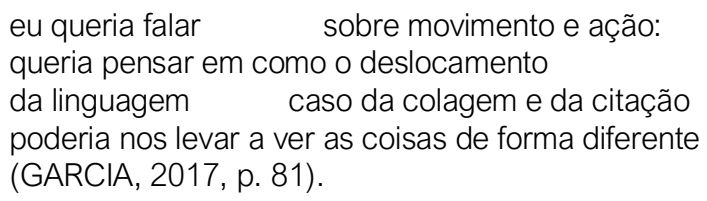

Num tempo de experiências vertiginosas, a poesia de Marília Garcia cria uma demora pela repetição de versos ao longo de um mesmo poema, pelos espaços em branco, pelos poemas longos, pelas várias perguntas feitas e deixadas em aberto no decorrer do livro. Mas uma demora que não se associa à passividade ou à inércia, mas à possibilidade de intervenção ativa nos textos e demais suportes. Retirando frases e palavras de seu lugar de origem e as reintroduzindo no poema ao lado de outras, novos sentidos (e ritmos) surgem. Muitas vezes a poeta opta, na feitura de um poema, por reorganizar uma notícia por ordem alfabética, ou mesmo um poema mais antigo seu, ou um livro inteiro de outro autor, como faz com A teus pés, de Ana Cristina Cesar:

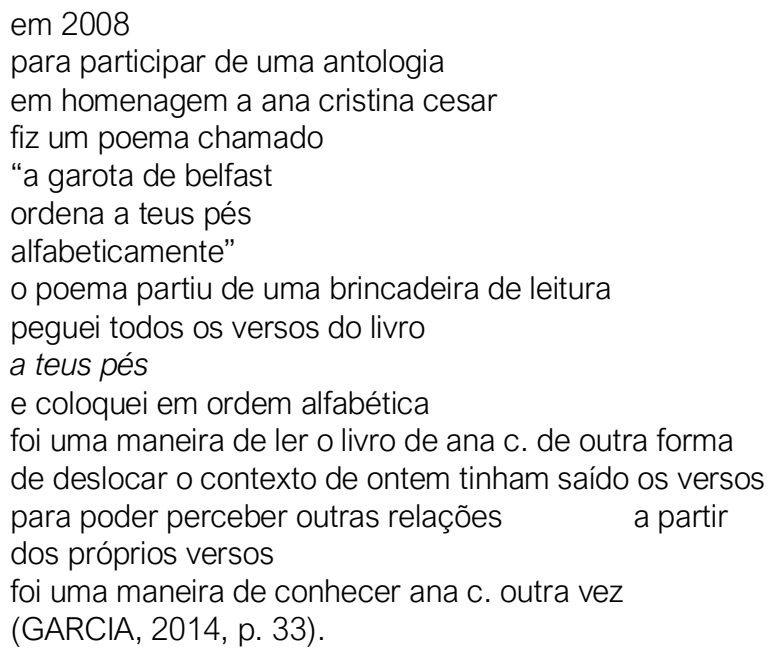

Esse "ver outra vez", movimento tão acessível devido ao desenvolvimento da tecnologia e da internet, que permite que nada desapareça completamente, em Marília Garcia não significa ver de novo da mesma forma e para sempre, mas descobrir e/ou criar, pela repetição (do que foi copiado e colocado num lugar diferente do seu lugar de origem), algo que ainda não tinha sido apreendido ou que ainda não estava ali. É como se a poeta se apropriasse no texto (mas também fora dele, uma vez que também faz produções poéticas em outros suportes, como vídeos, desenhos) de técnicas da cultura digital justamente para tensioná-las, ao ponto dessas técnicas e movimentos que 


\section{$=$ TRAMA $=$}

reproduzimos diariamente e mecanicamente em nossos computadores, celulares e tablets serem capazes de dizer algo diferente do que costumam nos dizer.

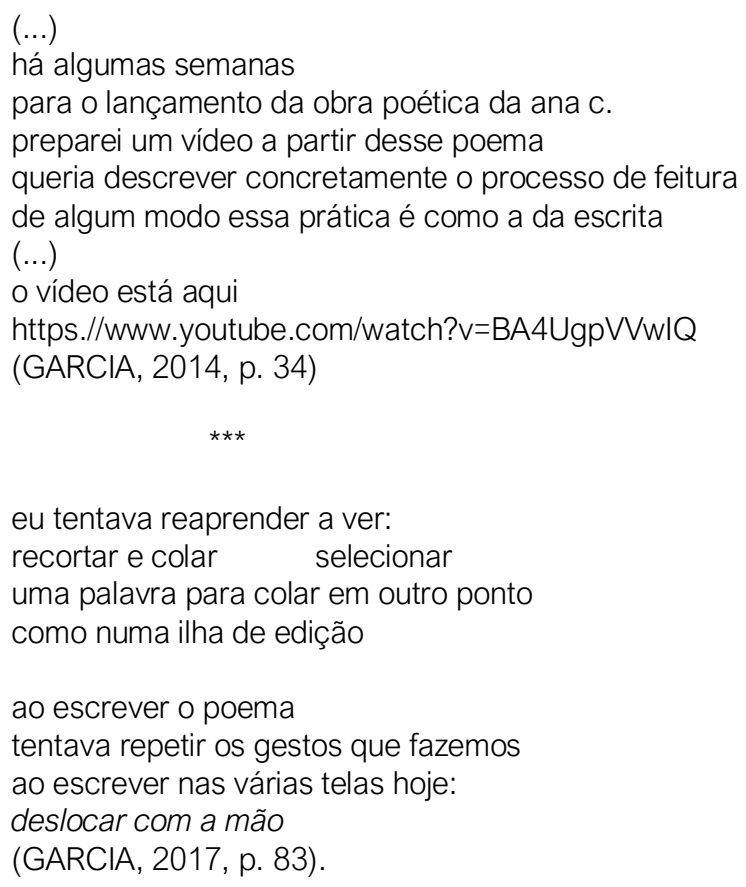

\section{DESLOCAMENTOS, LEITURAS}

A poesia de Marília Garcia nos lembra do que escreveu Rolland Barthes (1988) sobre "escrever a leitura". Seus poemas, por meio da cópia, da colagem e da repetição escrevem a leitura, a leitura "ao mesmo tempo irrespeitosa, pois que corta o texto, e apaixonada, pois que a ele volta e dele se nutre" (p. 40).

Trata-se, creio, de um "texto-leitura", de uma poesia-leitura: os poemas são também o próprio movimento de ler, que é um movimento, como diz Barthes, de levantar e abaixar a cabeça, não por falta de interesse, mas por "afluxo de ideias, excitações, associações" (p. 40).

A leitura dos poemas de Marília permite que o leitor entre em contato com um modo de ler que ele também pode exercer: uma leitura pessoal, mas que se apropria da vOz do outro, dos tantos discursos proferidos, para criar, a partir do outro, algo novo, sobre si e sobre o mundo, criando, como defende Florencia Garrumuño, novos sentidos de comum, novas comunidades.

Numa época em que há tantos textos online, sejam digitalizados ou criados já nessa plataforma, os procedimentos pelos quais Marília se vale e ressignifica em sua poesia podem nos instigar a fazer o mesmo. Claro, não se trata necessariamente de querer fazer poesia o tempo todo com os vários textos que lemos, mas de entender os textos e as tantas mídias que circulam como algo em que podemos, pela leitura, mexer, mudar, criar em cima, fazê-las desdizer e dizer outras coisas, fazê-las falar algo sobre nós através do outro. Compõem uma espécie de território comum no qual os modos de movimentação não precisam (e nem devem) se manter padronizados e regulados. Pois se mostra possível, e conscientemente explorável, praticar também nesse território expandido a mesma liberdade de ser de que a poesia tem dado testemunho em outras épocas e em outros terrenos. 
Essa ideia de fazer com que os textos nos digam algo, ou melhor, que possamos fazer os textos falarem algo sobre nós ou conosco, não deixa de tocar na questão tão urgente e cada vez mais discutida do sujeito leitor como figura central do ensino da leitura literária. A perspectiva de um ensino de literatura centrado no sujeito leitor, uma vez que leva em conta a dimensão subjetiva da leitura, agita a compreensão corrente de que ensinar literatura é transmitir uma interpretação correta e única, objetiva, muito bem justificada pela historiografia e pela crítica, a um outro que tudo ignora.

Nesse sentido, é interessante que a leitura cursiva, isto é, a leitura mais livre, espontânea e pessoal, encontre espaço também no lugar público das salas de aula, articulando-se, inclusive, com o que chamamos de leitura analítica, aquela que considera os estudos dos aspectos objetivos e formais das obras literárias, para que enfim esse sujeito leitor apareça, sendo visto e se fazendo ver - aspectos que, como vimos, a poesia de Marília Garcia veicula. (E talvez o melhor incentivo à leitura da literatura brasileira seja a própria leitura).

A poética do deslocamento de Marília Garcia oferece uma forma de incentivo à leitura que é da ordem do prazer, e não da obrigação. Trata-se de ler textos pela possibilidade de atuar neles e com eles, de fazer junto. O sujeito poético de um teste de resistores e Câmera lenta é, nesse sentido, um sujeito leitor: leva em conta a dimensão subjetiva da leitura, o modo como reorganiza as obras e se constrói com elas intimamente. Como o sujeito leitor de que fala, por exemplo, Annie Rouxel (2012), o sujeito poético em Marília Garcia é um sujeito móvel, que se faz e desfaz no decorrer dos textos lidos - e assim promove, conosco, a prática desse fazer-se e desfazer-se na ação de objetificar, em prol de nós mesmos, o acúmulo midiático em que vivemos.

A maneira que mais me parece ser possível de entusiasmar outras formas de pensar, de estar no mundo, de se reconhecer e desconhecer, e sobretudo o interesse em implicar-se na leitura literária, é falar da literatura e da experiência da leitura de um modo que as perguntas nunca se encerrem; fazer ver que é preciso fazer outras perguntas, fazer com que o desejo de fazer perguntas dure. Procurar mostrar que no centro do poema, do conto, do romance, há outro poema, conto, romance - algo que sem dúvida a poesia de Marília Garcia propõe e incentiva.

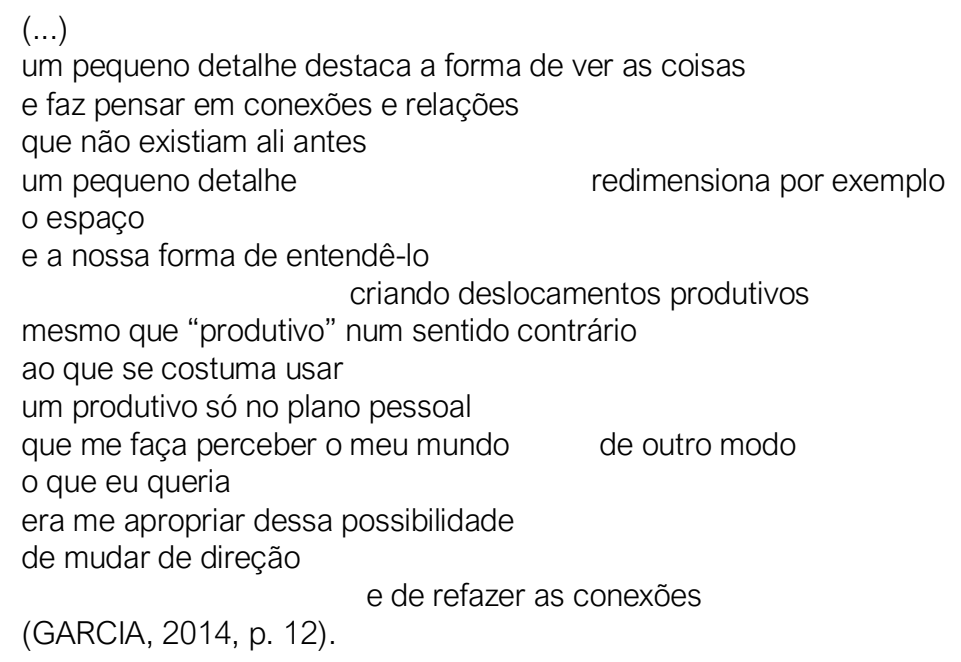




\section{$=\mathrm{T} R A M A=$}

\section{CONSIDERAÇÕES FINAIS}

Segundo Silvina Rodrigues Lopes

(...) Pela linguagem, o poeta situa-se numa já relação com o comum - com sentimentos, ideias e afectos partilháveis; com uma potência da redescrição (criação/transformação) do mundo - e vai interferir no comum.

(...)

Tal como só pode originar-se da experiência, um poema destina-se sempre à experiência de quem lê, ao contínuo movimento de recomeço tangente à história individual, e faz ressoar nela os espaços-tempos não mensuráveis. À anomalia da experiência poética, só uma outra anomalia, a da leitura enquanto acto igualmente sem medida, pode responder.

(2019, p.171).

Marília Garcia, ao utilizar os procedimentos já mencionados aqui, põe-se, como menciona Silvina Rodrigues Lopes, em relação com o comum, isto é, realiza uma poesia que fala com ao invés de uma poesia que fala de. Assim, nesse falar com, propõe uma poética que, embora seja do deslocamento, é também uma poética do encontro.

É certo que quando pensamos sobre a sociedade contemporânea, sobre a cultura digital, sobre a cultura que quer se fazer única, pensamos em aceleração. Aceleração do consumo, consumo material e imaterial, do desenvolvimento tecnológico, da destruição veloz e voraz de recursos naturais, do frenético fluxo de informação da internet. Mas a partilha que Marília parece se interessar em propor a partir de seus textos não é a partilha da rapidez. Por meio de procedimentos como os de copiar, colar e repetir, a poeta propõe uma desaceleração conjunta, em que os corpos (o do poema, o do autor, o do leitor, o da literatura) se movimentem lado a lado, de verso a verso, de poema a poema - "eu queria que fosse uma fala com // talvez uma fala de aproximação e de encontro". Ao invés de falar de, falar junto: é o desejo impresso nos últimos versos do poema "estrelas descem à terra (do que falamos quando falamos de uma hélice)", texto que encerra o livro Câmera lenta.

\section{REFERÊNCIAS}

BARTHES, Rolland. Aula inaugural da cadeira de Semiologia Literária do Colégio de França. São Paulo: Editora Cultrix, 2004.

O rumor da língua. São Paulo: Brasiliense, 1988.

CÁTROPA, Andréa. Para onde nos levam as hélices do poema? Estudo de literatura brasileira contemporânea, n. 55, 2018.

FRIAS, Joana Matos; SILVA, Sofia de Sousa. Apresentação. Revista eLyra, n. 7, 2016.

GARCIA, Marília. Câmera lenta. São Paulo: Companhia das Letras, 2017. um teste de resistores. Rio de Janeiro: 7Letras, 2014.

GARRAMUÑO, Florencia. Frutos Estranhos: sobre a inespecificidade na estética contemporânea. Rio de Janeiro: Rocco, 2014

KRAUSS, Rosalind. "Sculpture in the expanded field". In: October, n. 8, 1979

LOPES, Silvina Rodrigues. A anomalia poética. Belo Horizonte: Chão da feira, 2019.

MICHAUX, Henri. A verdadeira poesia faz-se contra a poesia. Cadernos de leituras (Chão da feira), $n$. 12, 2011.

PEREC, Georges. L'infra-ordinaire. Paris: Le Seuil, 2015.

RIAUDEL, Michel. "O autor invisível: tradução e criação na obra de Ana Cristina Cesar". In: Sereia de papel: visões de Ana Cristina Cesar. Rio de Janeiro: EdUERJ, 2015.

ROUXEL, Annie. Práticas de leitura: quais rumos para favorecer à expressão do sujeito leitor? Cadernos de Pesquisa, v. 42, n. 145, 2012.

SANTIAGO, Silviano. "Singular e anônimo". In: Poética. SP: Companhia das Letras, 2013, p. 452. SÜSSEKIND, Flora. Até segunda ordem não me risque nada: os cadernos, rascunhos e a poesia-emvozes de Ana Cristina Cesar. Rio de Janeiro: 7Letras, 1995. 